\title{
The Visible Human Project
}

\author{
Michael J. Ackerman* \\ U.S. National Library of Medicine (retired), MD, USA
}

\begin{abstract}
This paper gives a flavor of Dr. Donald A.B. Lindberg's view of the expanding role of libraries, his curiosity, and his tolerance for taking educated risks, through the creation and nurturing of National Library of Medicine's Visible Human Project. That project produced the Visible Man and Visible Woman datasets and a suite of tools for presenting and analyzing those and similar datasets. The results are used in teaching anatomy and other medical school courses and in software from the open-source Insight Tool Kit (ITK) that is included in many if not most volume-reconstructing systems. This story is a bit personal. From the beginning we recognized and understood each other since we were both "boys from Brooklyn".
\end{abstract}

Keywords: Donald A.B. Lindberg, U.S. National Library of Medicine, Visible Human Project, Insight Tool Kit

Donald A.B. Lindberg M.D.'s vision for the future, his love of scientific adventure, and his leadership skills made the Visible Human Project possible. I had joined the U.S. National Library of Medicine (NLM) early in 1987 as the Chief of the Educational Technology Branch in the Lister Hill National Center for Biomedical Communication (LHNCBC). My assignment was to demonstrate to American medical schools that microcomputers could and should be used as teaching tools within their curricula. It was the era of the IBM Personal Computer AT and video discs. A video disc player could be interfaced to and controlled by the microcomputer. The microcomputer could present the curriculum content and command the videodisc system to present an appropriate image or video. NLM had developed a video disc of pathological images, Dr. Lindberg's medical specialty, suitable for use in medical school curricula.

As part of my job, I traveled to several medical schools to give seminars on microcomputer-based education and the assistance that NLM was prepared to provide. In the fall of 1987, I made such a presentation at the University of Washington in Seattle. After the talk, Cornelius Rosse M.D., the Chairman of the Biological Structure Department, told me that if interactive microcomputer-based education is to be used in medical school, it should be used in the teaching of Anatomy. He explained that a student gets to see a particular anatomical site only once, since it is later dissected. The student cannot go back and review. Also, anatomy is three dimensional yet the student gets to see it only from one direction. One cannot really "study" anatomy like one studies other subjects. But image-based interactive computer programs would allow a student to re-experience a cadaver's dissection, to review it, and to "study".

\footnotetext{
*E-mail: mjackerman.t2i@gmail.com.
} 
That conversation made me think. Would focusing on anatomy provide the example that would get medical schools to adopt interactive technologies? When I returned to NLM, I went to see Harold M. Schoolman M.D., NLM's Deputy Director for Research and Education. Dr. Schoolman told me that Dr. Lindberg had commissioned a Long Range Plan shortly after he became NLM Director in 1984 . He explained that if I wanted to interest Dr. Lindberg in such an adventure, I would first have to show how my idea could support what had in January 1987 become the NLM Long Range Plan, particularly the underlying documents supporting recommendation 5.3.2, which says that "NLM should thoroughly and systematically investigate the technical requirements for and feasibility of instituting a biomedical images library" $[1,2]$.

With this advice in hand, I visited Daniel Masys M.D., the LHNCBC Director. He suggested that we organize and hold a workshop to explore what a three-dimensional digital data set of human cadaver anatomy images might be used for, particularly by an Anatomy Department. We did just that, and the workshop's recommendations appeared as an LHNCBC Technical Report in the fall of 1988 [3].

I was almost ready to visit Dr. Lindberg, but I first discussed my ideas with various colleagues. The majority thought that it was a bit crazy. But not Dr. Lindberg. He listened, seemed interested, asked questions, and assigned some homework. He seemed intrigued and left me feeling encouraged. I was thrilled that the answer wasn't no!

In the spring of 1989, Dr. Lindberg and I attended an International Medical Informatics Association (IMIA) International Symposium on Medical Informatics and Education held on the campus of the University of Victoria in Victoria, Canada. School buses provided transportation to the conference dinner, which was held some distance from the symposium location. I took a seat on the bus, and Dr. Lindberg took another in the row in front of me. During our journey to dinner, he turned around and asked me a question: If he were to allow my proposed anatomical imaging project to proceed, would I take the leadership role? Without hesitation I said yes, and without hesitation he said that we would do it. Then he asked what the project should be called. I said the Visible Man. He asked what about a woman. I could have said if we use a female cadaver we will call it the Visible Woman, but I quickly decided to see if this might be an opportunity and said that we can call it the Visible Couple, implying two cadavers. He thought for a moment and said, "Let's call it the Visible Human", the same name for one or two cadavers. The answer to doing two cadavers wasn't no!

Soon it was time to submit proposals for NLM's annual budget process. I prepared and submitted a budget proposal and justification for the Visible Human Project assuming two cadavers, one male and one female. This was the first time I actively participated in the NLM annual budget process so I was not alarmed when I didn't receive any feedback for my proposal. When the budget was announced, it contained a budget line for the Visible Human Project. The approved budget was what I had proposed for the first of three years. I called Dr. Lindberg to thank him and promised to immediately start the contracting process. He said stop. The money was not to begin doing the project, but rather the money was to pay the costs of an NLM Board of Regents (BoR) Special Committee to decide if the project should be done. "But you said that we were going to do the project", I questioned. "We will", he responded, "but after it is approved by the Board of Regents". "What if they don't agree?" I protested. "They will approve the project", he said with confidence. "That's my job." What I had experienced was an example of Dr. Lindberg's gift of knowing when and how to take educated risks.

With the go ahead from the NLM BoR, Dr. Lindberg assembled an NLM Board of Regents Long Range Planning Panel on Electronic Imaging. The panel was made up of 24 people, each representing an 
area of medicine, computer science, or entertainment in which images were of prime concern. The panel held three formal meetings over a nine-month period, at the end of which they issued a report, Electronic Imaging: Report of the Board of Regents, which not only approved the project but also suggested a budget, the steps necessary to successfully execute the project, and follow-on projects [4]. It was a blueprint for managing the Visible Human Project. And, as he had promised, the new fiscal year budget contained a funded budget line to implement the Visible Human Project.

The Visible Human Project would include separate collections of images from a male and a female cadaver. There would be CT serial cross-sectional images, MRI serial cross-sectional images, and anatomical serial cross-sectional images, each from head to toe. The Request for Proposals stipulated that the serial cross-sectional images in all three modes had to correspond with each other: Each CT crosssectional image had to correspond with a specific MRI cross-sectional image, which had to correspond with a specific anatomical cross-sectional image. The driving principle was that while clinicians can review radiological images, they have to treat the patient's anatomy. A computer program could overlay related images so the student could learn to recognize anatomy through the corresponding radiological images.

The dataset of the digitized images was estimated to be about 15 gigabytes in size. In 1990, a digital dataset of that size was almost unthinkable. The largest portable data storage medium at the time was the CD ROM, which holds about 0.7 gigabytes of data. The NLM BoR Planning Panel on Electronic Imaging discussed the dataset distribution problem and agreed that there would eventually be a solution. Dr. Lindberg never showed any hesitancy related to this issue.

The Visible Human Project Request for Proposals was advertised, bids were received, questions were asked of the bidders, answers were received, and a decision was made. The contract was sent to Dr. Lindberg's Office for his signature. He wanted to see me. "How was this decision made?" he asked. I started to explain the process. He stopped me. "I want a written report that documents the process, lists the expert panel members, and presents their justification for choosing the successful bidder." I could tell from Dr. Lindberg's tone that it would do no good to protest or explain. It took over a week to put together the report. I was called to his office a few days after I submitted it. He had the contract with him. He signed it, gave it to me, and wished me luck. I didn't ask any questions. I thanked him and left.

I really never thought about the incident until about 20 years later. Dr. Lindberg and I were at a professional meeting dinner where he approached me and apologized for the very hard time he gave me over the contract for the Visible Human Project. Before I could say anything, he explained: "One of the bidders was from outside the United States. If that bidder were given the award and then something went wrong, there would at least be a chance of successfully explaining it to Congress. But the award was made to an institution in Denver, Colorado, the heartland of the United States. Your procedures and justification were so good that there was no way to disqualify your recommendation. But now that the project is such a great success, I need to apologize. You made the right decision". I was speechless, and at that point learned a lesson in what taking educated risk was all about.

It was the job of David Whitlock M.D. and Victor Spitzer Ph.D. of the University of Colorado Denver, the principal investigators of the winning contract proposal, to find appropriate cadavers from which to create the anatomical cross-sectional images specified in the contract. Two years went by with no luck. Then Dr. Spitzer called me with a question. Some of the prisoners on death row in Texas had willed their bodies to science, and the Project was offered the cadavers. I decided that this was a question for 
Dr. Lindberg, and he in turn called for a special NLM Senior Staff meeting. The question at hand was more than a one of legality and ethics; it was also a question of optics. The history of the modern study of anatomy began with robbing the graves of murderers for their cadavers. Were we not repeating history? Dr. Lindberg led the discussion. All present agreed that they knew of no federal law or rule that prohibited accepting the offer. For example, HIPAA rules presented no issues because the deceased have no HIPAA protection. On personal ethics, no one present voiced an objection. But the optics were of concern. After some discussion, Dr. Lindberg suggested a solution: Accept the donations, but be totally transparent about the nature of the donations in any announcements that would be made when the datasets were made publicly available. NLM would hold back only the names of the deceased. The argument was that if NLM were not totally transparent, the press might fill in the blanks with misinformation that might cause more problems than the truth. There is historical justification for this approach in that there is a tradition in medicine of never revealing the identity of a volunteer subject. We agreed that NLM would never reveal the name of the subjects.

Several months went by before Texas sent a very fresh cadaver to Denver. I was notified early in the morning that the cadaver had arrived and that our CT and MRI scan protocols had begun. By noon, less than 12 hours after the death, I was told that the cadaver was unexpectedly showing signs of decomposition. By 3:00 pm I was informed that the cadaver rapidly decomposed to the point that it was useless and it would be disposed of. What happened?

It took some time to discover that potassium had been a component of the lethal injection. Its purpose was to stop the heart. But potassium has another effect. It causes the breakdown of cell membranes that in turn causes a general decomposition of the body. I always kept Dr. Lindberg and NLM Senior Staff informed about this project at their regular meetings. I told this story at the very next meeting. Dr. Lindberg immediately slammed his hand down on table and cried out, "Oh no, he was right". There was an immediate silence in the room. I was stunned. I said, "I'm sorry, but did I say something wrong?" I'm an engineer, not a physician, and sometimes I get my technical medical terms mixed up. "No", he said. "I just remembered. When I was a pathology resident, the old man in the pathology morgue told us that if a cadaver ever arrives with a high serum potassium level, do what you need to do as soon and as fast as possible because they are nothing but trouble. The old man was right." So, I asked Dr. Lindberg, "We are here in the National Library of Medicine with the world's medical literature. Where is this written?" Dr. Lindberg answered, "It isn't. But the old man knew!"

From that point on, the Project moved ahead with few dramatic surprises, but it certainly benefited from technological advances. Digital image capture technologies had become easier and better by then. The budget for the Project allowed for anatomical images to be captured on film, which would be digitized later. In addition, digital cameras had by then become reliable enough and capable of enough resolution that we wanted to add a digital camera so we could capture the digital images directly. Those cameras were still very expensive, but Dr. Lindberg supported the budget addition that let the Project also use a digital camera.

Drs. Spitzer and Whitlock learned many lessons while collecting the serial cross-sectional images of the male cadaver. As they were sectioning and imaging the male cadaver every $1.00 \mathrm{~mm}$, they were realizing that they could in fact capture serial digital images every $0.33 \mathrm{~mm}$. Three times the number of images of course meant three times the work and three times the cost. In this and in every other case, Dr. Lindberg enthusiastically supported the proposed improvements and increased the Project's budget, which slowly doubled, from $\$ 700,000$ to $\$ 1,400,000$. Dr. Lindberg never complained and never viewed 
these increases as cost overruns. They were improvements to the end product that took advantage of the latest in digital technologies, technologies that were not available when the Project was envisioned or awarded.

It also meant the dataset would be about three times the size, 40 gigabytes. It was now 1994. The speed of the national Internet had increased to the point that transferring a dataset of this size was almost practical. The original distribution problem was solved.

The availability of the male Visible Human Dataset was announced at the Annual Meeting of the Radiological Society of North America (RSNA) in Chicago in November 1994. Dr. Lindberg joined Drs. Spitzer and Whitlock and me for the announcement. He proclaimed his support and gave full credit to the people who had created and guided the project and successfully carried out the work. A year later, with Dr. Lindberg present in the same venue and in the same way, the availability of the female Visible Human Dataset was announced.

By January 1998, I had been working with Dr. Lindberg at NLM for ten years. When Dr. Lindberg decided that a presentation on the successful Visible Human Project should be on the agenda for the next NLM Board of Regents, I had the opportunity to try out my version of Dr. Lindberg's use of educated risk. He wanted part of the presentation to be a demonstration of an application that used a Visible Human dataset. I knew whom to invite. Dr. Lindberg asked if I would guarantee that the demonstration would work. "Of course it will", I answered affirmatively and enthusiastically. I invited Gregory Merril, the CEO of HT Medical, to present his company's Virtual Bronchoscopy System. The presentation and demonstration were scheduled for just after the morning coffee break. When I arrived at NLM that morning, I had an idea. Mr. Merril was setting up the demonstration. I asked him if he could guide someone else who would do the actually demonstration. He said that he could and asked who I had in mind. "Dr. Michael DeBakey", I answered. During the coffee break I asked Michael DeBakey M.D. if he had ever done a bronchoscopy. He said he had done them many times, so I invited him to do the virtual bronchoscopy demonstration. He was delighted.

Then I realized that I had not yet told Dr. Lindberg. "You are sure that this is going to work?" was his tentative response. "I guaranteed it to you", I again enthusiastically responded. I could hear in his voice that he was not fully convinced, but he decided to let me go through with it. Dr. DeBakey performed the bronchoscopy flawlessly, and the virtual system performed flawlessly too. The demonstration was set up in a way that Dr. DeBakey's view through the bronchoscope was projected on a big screen so that everyone in the room could see it. According to the minutes of the meeting, "Dr. DeBakey described what he was "seeing" in the lungs and, when he was finished, he said that what he and we had seen was, in fact, very real" [5]. At the next break Dr. Lindberg told me that he never had any doubts.

The Visible Human Project was a complete success. It was used in high school, college, and medical school teaching; imaging algorithm development, testing, and comparison; physiological and radiation modeling; art; and digital network testing. Dr. Lindberg became aware that the Exploratorium, a Science Center, in San Francesco had created life size Plexiglass "books" of the male and female Visible Humans. They were created for an exhibit which was being closed. As the Director of NLM he saw an opportunity for a unique acquisition for the library's book collection and offered to buy the "books". NLM acquired the "books" for the cost of shipping, and they became part of a new Visible Human Exhibit where they were prominently displayed in the NLM Visitor Center (Photo 1). 


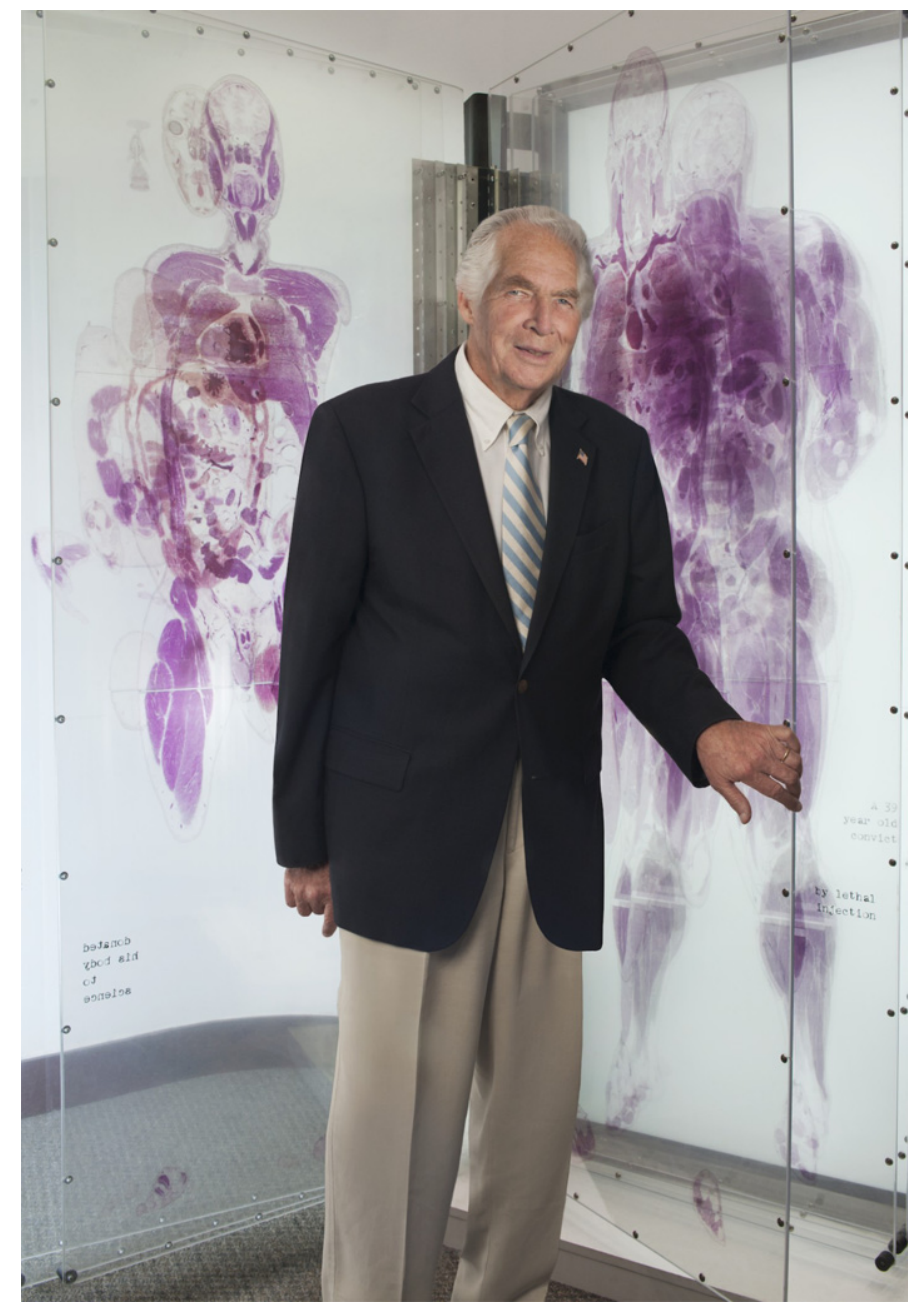

Photo 1. Dr. Lindberg stands among the Visible Human Plexiglass 'books' in the Visible Human Exhibit at NLM's Visitor Center. Photo credit: Jessica Marcotte.

It took about two years before we heard any criticism from the anatomical teaching community, our primary target. They reminded us that they taught anatomy by organ, not by cross-section. They suggested that we take the Visible Human serial cross-sections and reconstruct each of the body's organs from them. In order to do that, a map of each cross-section would have to be created showing to which organ each dot in the cross-section belonged-what's known as segmentation. Then the dots belonging to the organ of interest from each cross-section would have to be put back together - registration. This was then a manual process and was very time-consuming and very expensive. A few companies were doing it as part of developing their educational products. The integrated products were available, but the underlying segmentation and registration components were not. I realized that the next scientific challenge was to develop the algorithms that could automate the segmentation and registration processes.

Doing the segmentation and registration on Visible Human data would create the organ models only from the Visible Human datasets. Developing segmentation and registration algorithms would allow the 
anatomy community to have the organ models that they wanted based on the Visible Human datasets. It would also allow organ models to be created from any future Visible Human dataset, from NLM or elsewhere. Outside the anatomy community, it would, for example, allow the radiology community to reconstruct organs of interest from their serial CT and MRI images. Radiologists would no longer have to envision their serial images in three dimensions, making their work easier. Viewing and interpreting images with both non-radiology colleagues and patients would also become easier.

With this idea, with the target audience identified, and with estimates of how long it would take to accomplish and how much it would cost to complete, I asked for a special meeting with Dr. Lindberg. He listened, asked some questions and then said, "I guess the inexpensive part of the Visible Human Project is now over". The cost for creating the Visible Human datasets was \$1.4 million. My estimate of the cost of this new project was $\$ 7.5$ million.

A group of experts was formed to create these algorithms. NLM hosted their first meeting, to which Dr. Lindberg was invited. During the first coffee break, he informed me that I had a problem. "There must be more than a token woman who is knowledgeable in this area. Why are they not here?" Dr. Lindberg was always sensitive to representation and opportunity, of which this is just one example. I took the hint. And as was Dr. Lindberg's habit, he checked on my progress. I was happy to let him know that I had identified and recruited additional qualified women.

A little more than three years later, in 2002, the open-source Insight Tool Kit, ITK, was released [6]. It included segmentation and registration algorithms, and the anatomy community immediately found it useful. As predicted, ITK algorithms for three-dimensional reconstruction were soon included in radiological workstations, first by GE and Siemens and later by others. But it was also used by pathologists for volume reconstruction of serial pathology sections, by astronomers for volume reconstruction of their serial sections of the heavens, and by many other disciplines that were studying serial images from things that were size-wise in between.

In 2009, Dr. Lindberg and I planned one more major Visible Human-related project together. The question "Will NLM produce additional Visible Human datasets?" was asked at every Visible Human presentation. Additional datasets would represent the variability of human anatomy. We now had the means for segmentation and registration of any volume of interest in the Visible Human datasets. Why not create software that would allow the user to modify each volume of interest within realistic boundaries in order to build their own three-dimensional digital cadaver? The software would require a database containing the normal range of dimensions for each volume of interest in the body, i.e., organ, muscle, gland, blood vessel, bone, cartilage, etc. Dr. Lindberg suggested that we should first do the bones as they were the only body component whose size was constant, i.e., did not change when touched or with motion. I did some preliminary research, creating a digital folder filled with two gigabytes of papers from the anatomical variance literature, and then put together a proposal. By then the politics of agency funding had changed. Instead of a discussion on how the project would be funded, I was faced with Dr. Lindberg's question, "So what are you not going to do." I could see his uneasiness and frustration, but that was the reality of the time.

Each of the previous parts of the Visible Human Project could be characterized as high risk, high payoff when completed, with a reasonable chance for success. The same was true for the current proposal. Dr. Lindberg and I often realized that there were projects for which only the government could afford the risk. The budget and national policy could no longer support taking such risks in this domain.

NLM's continuing research funding under the Visible Human Project banner came to an end. My career had become defined by that project. Dr. Lindberg, whenever he mentioned the Visible Human Project in 
a talk, proudly said, "I gave him permission to take some time and do the project, and he hasn't had time to do anything else since". That's what two boys from Brooklyn were able to accomplish.

\section{References}

[1] National Library of Medicine, Board of Regents. Long range plan/report of the Board of Regents, National Library of Medicine [Internet], U.S. Department of Health and Human Services, Public Health Service, National Institutes of Health, Bethesda, MD, 1987 [cited 2021 May 17]. 67 p. Available from: http://resource.nlm.nih.gov/101646837.

[2] National Library of Medicine. Panel 5: Assisting health professional education through information technology. Assisting health professional education through information technology/report of Panel 5 [Internet], U.S. Department of Health and Human Services, Public Health Service, National Institutes of Health, Bethesda, MD, 1986 [cited 2021 May 22]. 40 p. Available from: https://collections.nlm.nih.gov/ext/kirtasbse/8706148/PDF/8706148.pdf.

[3] Lister Hill National Center for Biomedical Communications. Workshop on 3-D anatomical imaging, 1988.

[4] National Library of Medicine, Board of Regents. Electronic imaging: Report of the Board of Regents [Internet], U.S. Department of Health and Human Services, Public Health Service, National Institutes of Health, National Library of Medicine, Bethesda, MD, 1990 [cited 2021 May 9]. 36 p. Available from: https://collections.nlm.nih.gov/ext/ kirtasbse/9005059/PDF/9005059.pdf.

[5] National Library of Medicine, Board of Regents. Minutes of the Board of Regents [Internet], Department of Health and Human Services, Public Health Service, National Institutes of Health, National Library of Medicine, Bethesda, MD, 1998 [cited 2021 May 9]. 13 p. Available from: https://www.nlm.nih.gov/hmd/manuscripts/nlmarchives/bor/Jan1998.pdf.

[6] Kitware [Internet]. Kitware, New York, c1998-2021. ITK history [cited 2021 May 17]; [about one screen]. Available from: https://itk.org/about/\#history. 